\title{
24 Managing urban waste as a common pool resource
}

\author{
Jérémie Cavé
}

\section{Introduction}

In the experts' literature about solid waste management (SWM), the type of economic service that municipal solid waste management constitutes is not clear: is it a public service? Or is it a market economy activity? SWM is conceived variously as "a demand-driven business, a policy-driven activity and a public good" (UN-Habitat 2010: 164). The problem is that SWM is composed of many different tasks, which can be unbundled. Whereas street cleaning may be considered as a public good, the status of door-to-door collection is not as obvious: it still can be assimilated to a public good, yet it is one of the services "most easily converted to a private good, being divisible among consumers for services and payments" (Baud and Post 2003).

In 1994, a World Bank report, aimed at targeting the areas of potential private sector participation in the field of SWM in developing countries, proposed an economic characterisation of these successive tasks. Most of them were classified as public or toll goods. The sale of recyclables was presented as a private good. And the common goods box was left empty (Figure 24.1).

In contrast to this analysis, the idea of urban waste as commons may help us re-imagine urban policies beyond the state/market dichotomy that appears today as a structural axis of expropriation dynamics, especially in the Global South. Urban solid waste could fruitfully be conceived and managed as common pool resources. This would imply the attribution of use rights to a diversity of reclaiming and recovery agents and devices, in so far as they agree to some regulation and to channel their own refuse (derived from their recovery process) to sanitary landfills.

\section{Appropriation conflicts}

Defined as something thrown away, waste is an object that no longer belongs to anyone. Waste is what has been abandoned, i.e., res derelicta, things over which their former owners have renounced their property rights. ${ }^{1}$

The so-called "modernisation" process of SWM provokes clashes between agents: some experts invoke "contested" waste (Fahmi and Sutton 2010) whereas 
Public $\times$ Private Goods in Solid Was te Management

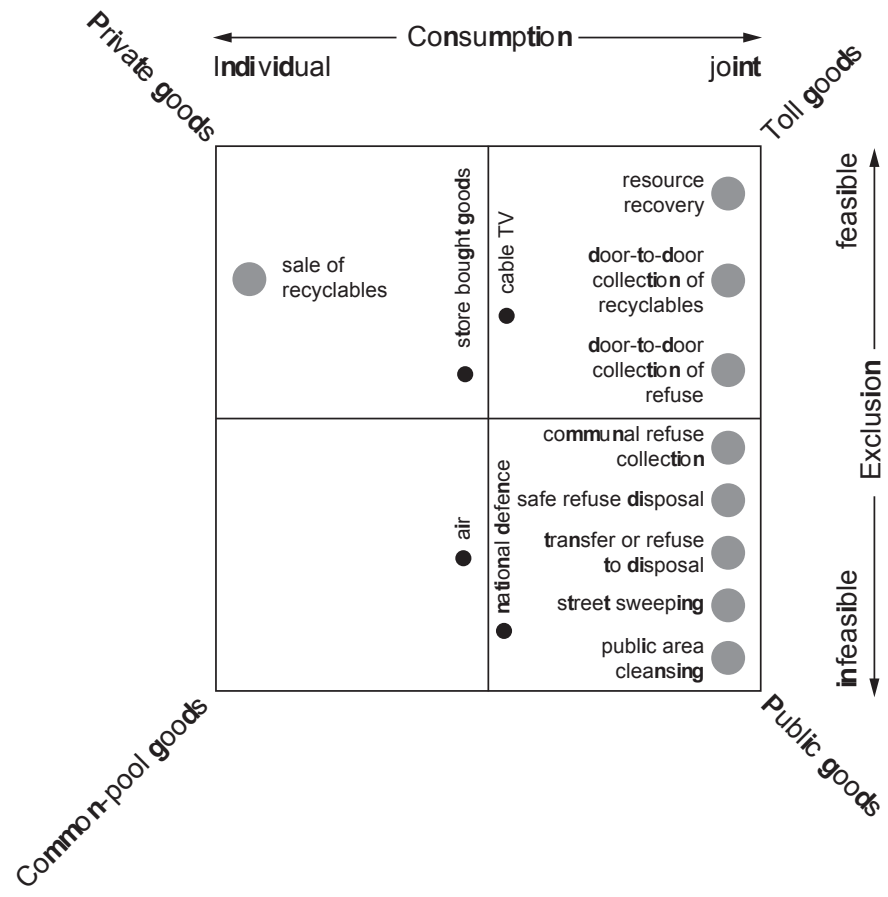

Figure 24.1 Public vs private goods in solid waste management.

Source: Cavé (2015: 121).

others talk of "competition" (UN-Habitat 2010: 8). Such "appropriation conflicts" (Cavé 2014) over SWM arise, pitting a variety of actors against each other (municipal authorities, private operators, waste pickers, residents' associations, industrial companies, etc.), because SWM is no longer only concerned with neutralising a nuisance, but also, increasingly, with recovering a valuable resource.

It is all the more critical to provide conceptual and operational tools to manage urban waste as commons today as most cities (focused on collection and disposal) do not recycle any of their waste while an increasing number of agents (including large private companies and producer responsibility schemes) now show an interest in waste management and recycling as a way to capture cheap raw materials: that is, in "urban mining".

\section{The urban solid waste deposit: an impure public good}

The nature of waste is by no means intrinsic. A specific plastic package may be seen as a useless residue until there is a shortage, at which point it is re-classified 
and re-valued as a commodity: "this is why what is waste today will not be waste tomorrow and why what was, common-sensically, waste yesterday is now incorporated as an economic 'sector'" (O'Brien 1999: 278). Precisely because of this fluctuating status, it is time to stop dealing with SWM issues in terms of the garbage/resource dichotomy, which ultimately implies a public/private good dialectic, and instead start considering urban solid waste holistically as a common good.

First, from a spatial perspective, the most lucrative items are gradually extracted ("creamed-off") from the solid waste stream through several stages of upstream interception. The fact that this urban service is provided on the streets (and not through an underground network), with successive offloadings, makes it possible and relatively easy for non-governmental actors to capture part of the flow. In other words, the way waste is managed makes it very difficult to exclude anyone from its appropriation.

Second, from an economic point of view, the reclaiming of recyclable solid waste constitutes a coveted objective for several actors. Far from being marginal or archaic, the informal recovery sector is embedded in the global industrial economy. The analysis of resale prices for reclaimed materials in south-east Brazilian cities demonstrates that the power of mechanisms aimed at catching dry waste rests on a non-elastic link to the global market demand for the corresponding virgin materials. ${ }^{2}$ In other words, the potential economic revenues from the trading of solid waste items are substantial. To this extent, waste is a rival good.

Being both rival and non-excludable, the urban solid waste deposit thus de facto appears as a common good. Neither pure resource, nor mere garbage, the urban solid waste deposit is always both.

\section{Would it be possible to manage urban waste as Common Pool Resources?}

When considering the entire deposit of urban solid waste as Common Pool Resources (CPR) as defined by Elinor Ostrom (Ostrom 1990), a distinction can be made between waste flows and stocks. Recognising this flow-stock structure in the SW deposit enables us to penetrate further into the internal dynamics of a common good. Indeed, according to Ostrom, any resource system is formed by these two interdependent components. The flow refers to units that are removed from the resource stock. The stock refers to units that are not removed from the resource.

- One portion of the urban solid waste deposit is quickly recovered or purchased and never actually ends up in a landfill. This part that is sufficiently valuable not to be discarded can be equated with flows.

- The rest of the deposit is permanently abandoned, of interest only to the municipal authorities. That fraction of the deposit, of zero or negative value, corresponds to a stock. There is no spontaneous incentive for anyone to get involved in its circulation. 
Mixed together, flows and stock constitute the solid waste deposit. Apprehending the urban waste deposit as CPR implies nonetheless the reversal of the internal dynamics of such a system:

- in the CPR described by Ostrom, the stock is necessary to the flow's renewal;

- in the case of solid waste, it is the opposite: the flow is paired with a stock that is potentially harmful and that, consequently, must not grow. And no-one wants to appropriate that stock.

In other words, the danger does not lie in the stock's exhaustion, but rather in its uncontrolled growth and disposal. Therefore, the risk that informal recovery agents are generating is that, by extracting the most lucrative section of the deposit, they could throw the municipal service off balance. Indeed, due to fact that reclaiming recyclables is largely done by informal agents, waste pickers as well as itinerant junk dealers and local shops, municipalities may not be able to compensate their collection and treatment costs with the revenue from the sale of recyclables. Consequently, the informal recovery agents' exclusive focus on recyclables (flows) may ultimately put the sanitary disposal of residues (stock) at risk.

According to Elinor Ostrom, appropriators of CPR are faced with two kinds of problems:

1 The first is rent dissipation. This refers, for instance, to the (economic) risk involved when separate door-to-door collection is implemented and the deposit is at the same time significantly creamed off upstream. This problem could be solved through the "way of attributing a fixed, time-independent quantity of resource units [to the various appropriators, so as] to reduce uncertainty and conflict over the assignment of rights" (Ostrom 1990: 64). In some Brazilian cities, for instance, informal agents agree to stop recovering recyclables from the streets provided that the municipality delivers to them the whole output of its separate collection scheme.

2 The second problem consists in the attribution of spatial or temporal access to the resource, as reflected in the interception dynamics observed in Vitória and Coimbatore (Cavé 2014). According to Ostrom, these kind of problems arise "because spatial and temporal distributions of common resource units frequently are heterogeneous and uncertain" (1990: 65). As long as recovery agents operate informally and/or illegally, it is very difficult for them to save and invest financial resources as they have no guarantee at all that they will be getting recyclables the next day and at a sufficient rate. They also do not care about what happens to final residues (stock) as they are frequently chased and repressed by the public agents in charge of it.

Mobilising use rights appears a promising lead. Use rights have been theorised, within the resource institutional regimes (RIR) framework, as an analytical and 
operational tool. Use rights are realised in the privileged access to a flow of resource units. Unlike property rights, use rights determine "who might have what use of which quantity of the resource, in the form of which goods and services derived from it" (Gerber et al., 2009: 7). Use rights thus refer to resource management and withdrawal rules that do not grant absolute freedom in the use of the resource. ${ }^{3}$ As a matter of fact, after a long and harsh struggle for the recicladores' rights, the Colombian Constitutional Court has warranted a "sure and safe access" to solid waste to informal recovery agents. ${ }^{4}$

\section{Concluding remarks}

Emanating from a combination of public and private law, use rights seem an appropriate prism through which to manage waste as a CPR. Taking into account the multi-segmented nature of the SWM service and the economic value of the flow part of waste - which make interceptions unavoidable - the assignment of targeted use rights could offer an innovative way to solve solid waste appropriation conflicts. Indeed, the main difference between attributing use rights rather than property rights is that it makes the appropriators accountable to a regulator for the whole flow's traceability. Indeed, the informal recovery circuits do generate various kinds of refuse (solid, liquid, gaseous) that today are disseminated in the environment without any supervision.

The inclusion of both stock (for minimisation) and flows (for maximisation) within the analytical framework of CPR, suggests the desirability of a semidecentralised SWM system. In such a system, non-governmental recycling initiatives would not be eradicated in favour of a monopolistic and centralised service focused on landfill solutions. Recovery agents would be incorporated as local players able to efficiently capture at source as much waste as possible. However, they would be included on the proviso that they would channel their own waste residues to the centralised treatment facilities in order to cope with environmental and sanitary externalities. Hence, stock management would be centralised, and flow management decentralised, as in the case of some Indian neighbourhoods or in Surabaya in Indonesia where waste separation, recyclables resale and composting are implemented at the Kampung (neighbourhood) level and final residues are removed to a centralised sanitary landfill.

\section{Notes}

1 Municipal authorities have the "responsibility" of dealing with waste; they do not own the waste.

2 Data from CEMPRE (Compromisso Empresarial para Reciclagem, www.cempre.org. br) shows the monthly resale prices communicated by a series of waste pickers cooperatives from the south-east of Brazil for the 2001-2010 period. The materials considered are: white paper, cardboard, aluminium cans, plastics soft and hard, PET. Average values were aggregated from: Vitória and Guarapari (ES), Itabira (SP), São José dos Campos (SP) and Rio de Janeiro (RJ). Data from London Stock Exchange (LSE) indicate the "fixing" commodity prices, from Société Générale systems, through one of 


\section{Jérémie Cavé}

their major providers, that is, Reuters. These are the daily readings, from Monday to Friday, from 3 September 2001 to 13 May 2010, which amounts to 2,194 readings.

3 Close to the notion of "operational level" rights (where we find access rights to CPR as well as resource's units removal rights) (Schlager and Ostrom 1992).

4 Auto 275/11. Available at: www.corteconstitucional.gov.co/relatoria/autos/2011/ a275-11.htm. 